\title{
Virginia Eubanks (2018) Automating Inequality: How High-Tech Tools Profile, Police and Punish the Poor. New York: St. Martin's Press. 260 pages. elSBN: 9781466885967
}

\author{
Ricardo Simmonds \\ ricardo@creatio.org
}

The allure of technology looms large in modern societies. Day to day we observe changing social behaviors from the way we type, pay for car rides, order food and dream of endless vacations in random people's homes. In Automating Inequality: How High-Tech Tools Profile, Police and Punish the Poor, Virginia Eubanks explores the impact of technology on the lives of the poor.

Eubanks central thesis is penetrating. For as long as we can remember human beings have been the protagonists of decision-making. However, since the dawn of the digital age much of that decision-making power has been handed over to sophisticated machines. Data collection provides the raw material for these machines, a reality "so deeply woven into the fabric of social life that, most of the time, we don't even notice we are being watched and analyzed" (p. 5). The marginalized are dependent on public services and endure more screening and surveillance than any other group. The poor are guinea pigs in a social data-driven experiment that has real impacts on their lives... and deaths.

Automating Inequality documents how poverty is being exploited and perpetuated in America through high-tech data. As a professor of political science, Eubanks is able to weave detailed investigative research with compelling personal stories. She guides the reader on a journey to explore the impacts of technology on the poor in Indiana, Los Angeles and Pittsburgh. While the tone of the book is not academic, it examines public policies and welfare programs in detail. The author is such a gifted storyteller that policy problems come to life in what feels at times like a heart wrenching documentary.

Sophie Stipes, to whom the book is dedicated, was the daughter of a poor family in Indiana. Born with cerebral palsy, 1 p36 deletion syndrome and back ridden for the first two years of her life, she eventually received a life-saving feeding tube and critical developmental assistance through Indiana's s Family and Social Services Administration (FSSA). Then, at the ripe age of six, Sophie received a letter (addressed to her) stating that Medicaid was being withheld due to a "failure to cooperate in establishing eligibility" (p. 42). The letter was delivered late, which gave little Sophie three days to solve the issue or lose Medicaid. Her family could not pay for her medical needs, which meant she would die.

In the background was a new 10-year \$1.16 billion state contract with IBM for the automation of the FSSA, which the state governor promised would improve efficiency and bring modernization. Automation streamlined processes from local offices to one main building and case inquiries to centralized private call centers. The results were disastrous: appointments could not be scheduled, call operators were not trained, eligibility error rates more than tripled, appeal cases were backlogged and 283000 documents 'disappeared', a 2,473 percent increase. As a result the state "denied more than a million applications for food stamps, Medicaid, and cash benefits, a 54 percent increase... prior to automation" (p. 51). 
In less than three years the governor of Indiana admitted to the failure of automation, cancelled the contract, and sued IBM for \$437 million. IBM countersued the state for $\$ 100$ million, won and later (upon appeal) the Supreme Court of Indiana recognized IBM's breach of contract as well. In the words of the judge who saw the case, the failure of automation was due to "misguided government policy and overzealous corporate ambition... both parties are to blame and Indiana's taxpayers are left as apparent losers" with nothing able to remedy the "personal suffering of needy Hoosiers" (p. 72).

Sophie fortunately did not make up those failed statistics - her mother found help from a well connected advocate who showed up at the governor's office, demanded an in person meeting and had her benefits reinstated the next day. Yet Sophie's triumph was the exception, not the rule. Eubanks guides the readers through detailed accounts of the tragedies of automation for homeless services in Los Angeles. In Pittsburgh, a predictive algorithm determines which children are most at risk from abuse and neglect before they are born; a number on the screen selects the parents that must hand their children to foster care.

In the cases of homeless profiling and especially foster care decision-making in Pittsburgh, Eubanks analyses algorithm development in more detail and teases out their social, cultural, political and racial biases. While there is little discussion about algorithm accountability, we are given a detailed description of the different variables that compose the foster care algorithm and how those variables affect outcomes. In one case, the algorithm employed by Alleghany County automatically triggers a welfare investigation for a child flagged with a high-risk score, effectively overriding human decision-making.

These diverse case studies span America and persuasively illustrate the close relationship between automation and increased hardship for the poor. However, we are also presented with a deeper thesis: high-tech-tools don't "profile, police and punish the poor" unaided. Rather, government officials are using technology as a tool to achieve welfare cost reducing policies through the backdoor. Eubanks argues that the same poverty discriminating logic that formed poorhouses in the early 1800's and scientific charity programs before the Great Depression is at work in the "digital poorhouse" of today. The digital poorhouse was born in the 1970's when elected officials "performed a political sleight of hand" by commissioning "expansive new technologies that promised to save money by distributing aid more efficiently, [but rather] these technological systems acted like walls, standing between poor people and their legal rights" (p. 33).

This historical account of poverty, technology and values constitutes both the greatest strength and weakness of the book. On the one hand, Eubanks is able to paint in broad strokes a cogent history of poverty related policies in America. She aptly describes technological developments and their interactions with poverty, welfare and key social historical contexts. One often finds nuanced distinctions and evaluations of different technologies along with their current and recommended alternative applications. There is a consistent positive and critical engagement with technology that assuages fears of luddism.

Unfortunately, the same distinctions and nuance are not observed when it comes to the engagement of values underlying poverty policies. The prescience of Automating Inequality is in part due to its willingness to engage the social welfare debate. However, in some instances, the language of Automating Inequality betrays unhelpful conflations and exaggerations. For example, welfarereducing proposals to date are collapsed into an "expansion and continuation of moralistic and punitive poverty management strategies that have been with us since the 1820s" (p. 37). And a Manichean tone emerges in moments of outrage against the "well-funded" movement that "manufactures and circulates misleading stories about the poor" and the "conservative critics of the welfare state [who] continue to run a very effective propaganda campaign" (p. 38).

Automating Inequality lacks a policy framework for dealing with the discussion of values around poverty and welfare. When values are discussed, they are often conflated into a historical narrative which is compelling but not carefully supported. This careless engagement of values may disenfranchise some readers who could be otherwise 
receptive and would most likely benefit from the important implications of technology driven social programs. By assuming a set of values and wearing them on her sleeve Eubanks misses an opportunity to broaden the discussion about policy alternatives available for addressing the automation of inequality.

However, there is a change of gear towards the last chapter and conclusion of the book. Martin Luther King's Jr. sermons turn the discussion away from value driven politics towards moral and religious considerations towards the poor. King reminds us that one day we will stand before the God of history who will ask about our actions. "Gargantuan bridges" and "gigantic buildings to kiss the skies" built with "scientific and technological power" will be met with "That was not enough! But I was hungry, and ye fed me not. I was naked, and ye clothed me not. I was devoid of a decent sanitary house to live in, and ye provided no shelter for me" (p. 216). Eubanks draws a powerful parallel to our modern day, where we will similarly claim to have built cars that drive themselves and designed bots that speak like humans, yet still we will be met with the same disapproving words in Matthew's Gospel.

In a religious and ethical key the political framing of welfare assistance is problematized and broadened. As Pope Francis recently remarked, "the Lord does not discuss theories of poverty and wealth". Jesus' commitment to the poor is undeniable, but it is also not absolute. In the very next chapter of Matthew quoted by reverend King, Jesus rebukes the disciples for wanting to sell expensive oil and give it to the poor (Mt 26). Based on this broader non-binary framework, the discussion of the implications of automation for society, democracy and the role of government is rich and thought provoking. The nuance and depth offered by a faith filled vision of poverty shows how complex social problems predate technological intervention, sets a high moral bar for evaluating the impact of algorithms on the poor and points towards different possibilities for integrating datadriven tools with human discernment. We are presented with creative and insightful recommendations for moving forward, such as a first draft of the Hippocratic oath for data scientists.

Most importantly, we are warned against the "magical thinking" that often accompanies technological developments. A technocratic mindset that is afraid or unable to grapple with social ills is too easily drawn to the scintillating promise and power of technological quick fixes. This "myopic focus on what's new leads us to miss the important ways that digital tools are embedded in old systems of power and privilege" (p. 178). Technology will not and cannot wipe away the very human problems that make our societies. Eubanks artfully pulls the veil of technology before our eyes and demonstrates how behind every algorithm and sophisticated model is a human input and ethical decision. 